\title{
Investigation of the Physical and Mechanical Properties of Hot-Pressed Boron Nitride/Oxide Ceramic Composites
}

\author{
Rodney W. Trice ${ }^{*}$, and John W. Halloran ${ }^{*}$ \\ Materials Science and Engineering Department, University of Michigan, Ann Arbor, Michigan 48109-2136
}

\begin{abstract}
Billets of hexagonal boron nitride powders $(h-\mathrm{BN})$ were hot-pressed, varying the alignment of the platelike particles and the amount of oxide additives. Increasing either alignment of individual grains or the amount of additives was shown to increase flexural strength, to approximately 120 MPa at ambient temperatures. $h$-BN was shown to deflect cracks initially propagating normal to its basal planes.
\end{abstract}

\section{Introduction}

$\mathrm{H}^{2}$ EXAGONAL boron nitride ( $h$-BN) has many unique engineering properties and uses. ${ }^{1-4}$ For example, additions of $h$-BN to alumina ${ }^{5}$ and silicon nitride $6-8$ improved thermal shock resistance. These improvements may be due to microcracks that exist between basal planes in $h$-BN. ${ }^{9-11} h$-BN can also be used as a weak interface between layers ${ }^{12}$ or filaments ${ }^{13,14}$ of silicon nitride. However, recent research has shown that interfaces created with $\mathrm{BN}$ powders often include a secondary phase. ${ }^{15}$

In the current research, the physical and mechanical properties of $h$-BN with varying amounts of an added secondary phase were studied to learn about the intrinsic properties of this common interface material. Also investigated in the current research was the role of $h$-BN grain alignment on crack deflection. Mechanical evaluations of strength were determined at room temperature.

\section{Experimental Methods}

Hexagonal boron nitride (Advanced Ceramics, HCP), consisting of platelike grains 7 to $10 \mu \mathrm{m}$ in diameter and 0.1 to 0.3 $\mu \mathrm{m}$ thick, was used to fabricate the composite billets. Its residual oxygen content was $0.4 \mathrm{wt} \%$. At this level of oxygen content, $h$-BN is not expected to sinter. ${ }^{16}$

Three configurations were investigated, varying the oxide

D. P. Butt-contributing editor

Manuscript No. 189952. Received August 17, 1998; approved June 11, 1999. Supported by DARPA/ONR under Contract No. N0014-95-0302.

*Member, American Ceramic Society.

${ }^{\dagger}$ Now at the Department of Materials Science and Engineering, Northwestern University, Evanston, Illinois 60208-0302. weight fraction and the alignment of the $h$ - $\mathrm{BN}$ as listed in Table I. The oxides added to the $h$ - $\mathrm{BN}$ were $\mathrm{SiO}_{2}, \mathrm{Y}_{2} \mathrm{O}_{3}$, and $\mathrm{Al}_{2} \mathrm{O}_{3}$, chosen to simulate the secondary phase observed in $h$-BN interfaces. ${ }^{15}$ The relative amount of each additive was kept constant according to $1.00 \mathrm{~g}$ of $\mathrm{SiO}_{2}: 1.34 \mathrm{~g}$ of $\mathrm{Y}_{2} \mathrm{O}_{3}: 0.18 \mathrm{~g}$ of $\mathrm{Al}_{2} \mathrm{O}_{3}$. The boron nitride and additives were ball-milled in methanol for $4 \mathrm{~h}$ with silicon nitride media before further processing.

$\mathrm{BN}$ billets were fabricated to give both highly aligned and less aligned microstructures. In the less aligned configuration, the $h$-BN/additive mixture was placed directly into a graphite die and hot-pressed. Billets BN-22LA (22 wt\% additives) and BN-31LA (31 wt\% additives) were fabricated by this method.

Several additional processing steps were required to align the basal planes of the boron nitride. In the first step, approximately $50 \mathrm{vol} \%$ boron nitride/additives were blended with poly(ethylene-co-ethyl acrylate) and methoxy-polyethylene glycol 550 in a high-shear mixer at $150^{\circ} \mathrm{C}$. The resulting ceramic/polymer mixture was subsequently pressed into a thin (2 $\mathrm{mm}$ ) sheet at $100^{\circ} \mathrm{C}$. The flow of the mixture under the applied load has previously been shown to align the platelike grains of boron nitride. ${ }^{13}$ Following the first pressing, the thin sheet was cut into $25.4 \mathrm{~mm}$ squares and stacked, one on top of the other. The stacked squares were then heated and pressed again. This stacking/pressing step was repeated twice more, with each subsequent pressing further aligning the boron nitride grains. The final pressed sheet was cut into $50 \mathrm{~mm} \times 78 \mathrm{~mm}$ sheets, stacked, and placed in a steel die. The sheets were warmpressed at $150^{\circ} \mathrm{C}$ and 3 to $4 \mathrm{MPa}$, melting the polymer binder and slightly compacting the stack. The end result was a 10 to $12 \mathrm{~mm}$ thick billet. Next, the billet was placed on a bed of silicon nitride powder in a tube-furnace and heated slowly to $700^{\circ} \mathrm{C}$ in flowing nitrogen to remove the polymer binder. Following cooling, a post-binder burnout heat treatment was performed in flowing air to remove residual carbon, heating the billet through $400^{\circ} \mathrm{C}$. The resulting billet was labeled BN-22HA.

All three billets were hot-pressed at $1740^{\circ} \mathrm{C}$ under an applied pressure of $25 \mathrm{MPa}$ for $1 \mathrm{~h}$ and $45 \mathrm{~min}$. The heating rate was approximately $600^{\circ} \mathrm{C} / \mathrm{h}$, and load was not applied until the temperature (measured off the surface of the die with a pyrometer) reached $1200^{\circ} \mathrm{C}$.

The $6 \mathrm{~mm}$ thick billets were machined to $4.5 \mathrm{~mm}$ by removing equal amounts of material from both sides, then cut into 3.8 $\mathrm{mm} \times 4.5 \mathrm{~mm} \times 48 \mathrm{~mm}$ flexure bars for 4-point flexural testing. The tensile surface was polished to a $3 \mu \mathrm{m}$ finish prior to

Table I. Physical Properties of the Three Monolithic BN Billets

\begin{tabular}{|c|c|c|c|c|}
\hline Sample & $\begin{array}{c}\text { Wt fraction of } \\
\text { oxide } \\
\text { additives }\end{array}$ & $\begin{array}{l}\text { Density } \\
\left(\mathrm{g} / \mathrm{cm}^{3}\right)\end{array}$ & $\begin{array}{l}\text { Oxides formed } \\
\text { by additives }\end{array}$ & $\begin{array}{l}25^{\circ} \mathrm{C} \text { strength } \\
(\mathrm{MPa})\end{array}$ \\
\hline BN-22HA & 0.22 & $2.37 \pm 0.02$ & $\begin{array}{c}\beta-\mathrm{Y}_{2} \mathrm{Si}_{2} \mathrm{O}_{7}{ }^{\dagger} \\
\alpha-\mathrm{Y}_{2} \mathrm{Si}_{2} \mathrm{O}_{7}^{\S}\end{array}$ & $117 \pm 14$ \\
\hline BN-22LA & 0.22 & $2.25 \pm 0.02$ & $\alpha-\mathrm{Y}_{2} \mathrm{Si}_{2} \mathrm{O}_{7}^{\ddagger}$ & $74 \pm 4$ \\
\hline BN-31LA & 0.31 & $2.43 \pm 0.02$ & $\alpha-\mathrm{Y}_{2} \mathrm{Si}_{2} \mathrm{O}_{7}$ & $105 \pm 6$ \\
\hline
\end{tabular}




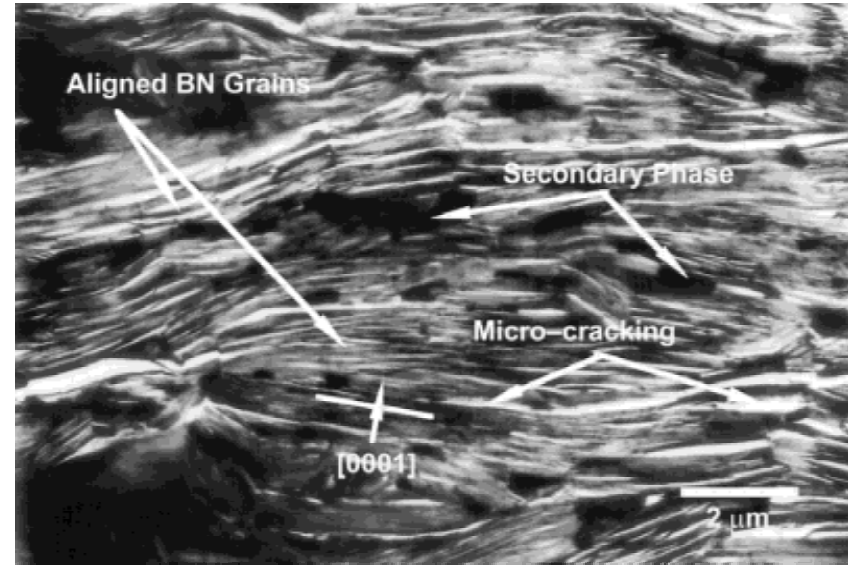

Fig. 1. Bright-field TEM image of BN-22HA. Note the alignment and microcracking between basal planes of boron nitride and the secondary phases that result from the oxide additives.

flexure testing. Density measurements were made on the same test specimens via the immersion method. ${ }^{17} \mathrm{CuK \alpha}$ radiation was used for the X-ray diffraction experiments.

Mechanical testing was performed on a commercial screwdriven load frame (Instron 4483, Canton, MA) equipped with a $5 \mathrm{kN}$ load cell and a fully articulated 4-point bend fixture. The inner and outer spans were fixed at 20 and $40 \mathrm{~mm}$, respectively. The strength of each test specimen was measured perpendicular to the hot-pressing direction. Three replicates were run for each billet, all at a crosshead speed of $0.5 \mathrm{~mm} / \mathrm{min}$.

A cross-sectional TEM specimen of BN-22HA was fabricated using the tripod or wedge polishing technique. ${ }^{14}$ The sample was ion milled on both sides simultaneously for approximately $1 \mathrm{~h}$ at a current of $0.5 \mathrm{~mA}$. A JEOL 2000FX $(200 \mathrm{kV})$ TEM was used to view the sample.

\section{Results and Discussion}

\section{(1) Physical Properties}

Table I lists the phases formed by the oxide additives during hot-pressing, as determined by XRD. Both $\alpha-\mathrm{Y}_{2} \mathrm{Si}_{2} \mathrm{O}_{7}$ and $\beta-\mathrm{Y}_{2} \mathrm{Si}_{2} \mathrm{O}_{7}$ were observed in BN-22HA; however, $\alpha-\mathrm{Y}_{2} \mathrm{Si}_{2} \mathrm{O}_{7}$ was observed only in BN-22LA and BN-31LA. No phases with aluminum atoms were observed.

Each hot-pressed billet was lubricious to touch and demonstrated good structural integrity. They were predominantly white when viewed in the hot-pressing direction and grayish when viewed normal to this direction (i.e., from the side). The grayish color was due to the manifestation of oxide phases primarily between the basal oriented grains of $h$-BN.

Figure 1 presents a bright-field TEM cross-sectional image from BN-22HA. The micrograph shows "stacked" grains of boron nitride with characteristic microcracking observed between basal planes. ${ }^{9}$ The oxide phases formed during hotpressing are the dark regions located between the $\mathrm{BN}$ grains. No amophous regions were observed using selected area diffraction techniques.

The densities of samples cut from each billet are provided in Table I. For reference, the theoretical densities of $\mathrm{BN}^{2}$ and $\alpha-\mathrm{Y}_{2} \mathrm{Si}_{2} \mathrm{O}_{7}{ }^{18}$ are 2.28 and $4.30 \mathrm{~g} / \mathrm{cm}^{3}$, respectively. Measuring approximately 25 vol\% oxide phase from Fig. 1 using a graphical method, a theoretical density of $2.8 \mathrm{~g} / \mathrm{cm}^{3}$ is calculated for $\mathrm{BN}-22 \mathrm{HA}$ and BN-22LA. Therefore, BN-22HA and BN-22LA are approximately $85 \%$ and $80 \%$ dense, respectively. In the calculation for $\mathrm{BN}-22 \mathrm{HA}$, we have not differentiated between the densities of a $\alpha$ - and $\beta-\mathrm{Y}_{2} \mathrm{Si}_{2} \mathrm{O}_{7}$ because of the difficulty in determining the amounts of each phase. BN-22HA demonstrated a higher density as compared to BN-22LA due to its highly aligned microstructure. Higher internal porosity would be expected in BN-22LA, due to unaligned grains prohibiting efficient packing. BN-31LA had a higher density than BN22HA due to its higher oxide content. The open porosity for all samples was very low, less than $0.2 \%$. This is likely due to smearing of the soft $\mathrm{BN}$ grains during polishing, closing surface porosity.

\section{(2) Mechanical Properties}

Table I presents the strength at room temperature for each of the three billets. For billets with equal amounts of secondary phase (BN-22HA and BN-22LA), an increase in strength was noted for the highly aligned billet. Figure 2 shows the microstructure from fractured $\mathrm{BN}-22 \mathrm{HA}$ and $\mathrm{BN}-22 \mathrm{LA}$ samples. The basal planes of the boron nitride powders are clearly highly aligned in $\mathrm{BN}-22 \mathrm{HA}$, oriented perpendicular to the hotpressing direction. In BN-22LA, the basal planes of many individual grains are oriented nearly parallel with respect to the hot-pressing direction. It is likely the $h$-BN platelets oriented perpendicular to tensile stresses (and parallel with the hot-

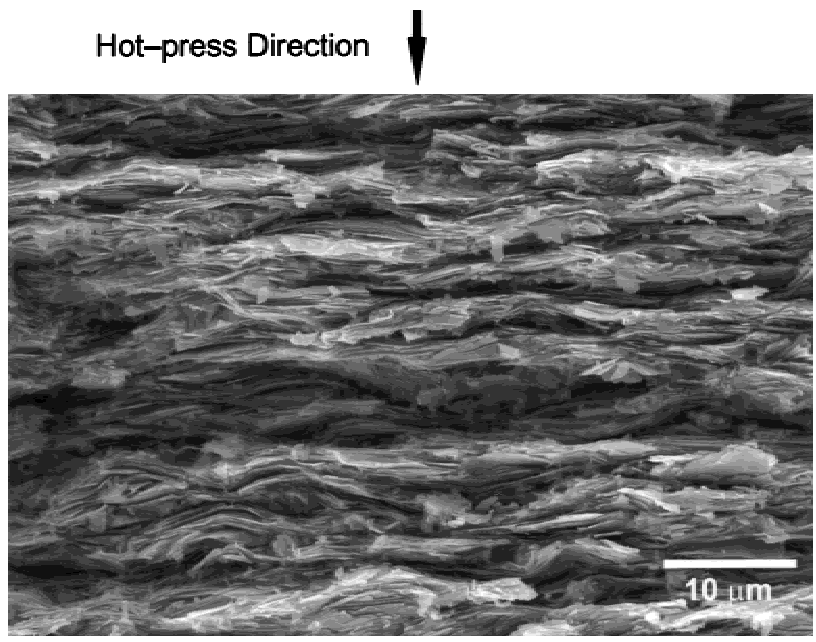

(a)

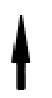

\section{Hot-press Direction}

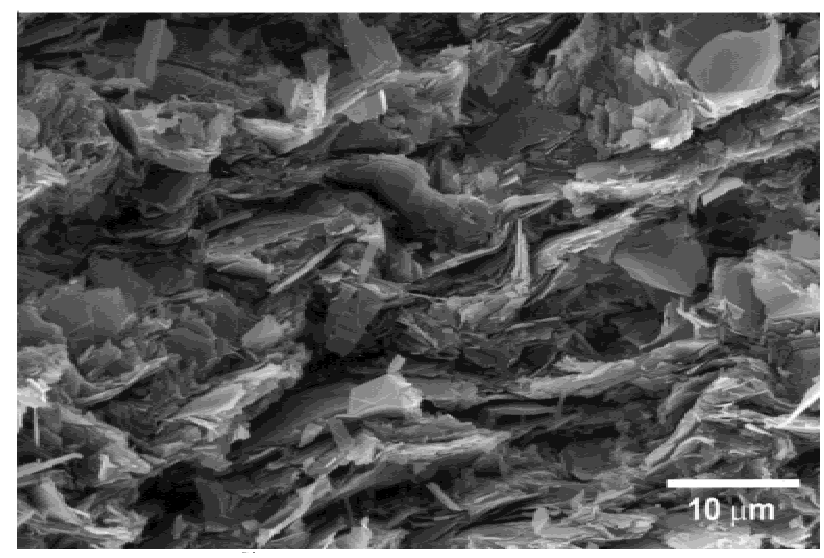

(b)

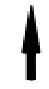

Fig. 2. Fracture surfaces of (a) BN-22HA and (b) BN-22LA. No basal oriented grains were observed parallel to the hot-press direction in BN-22HA. 


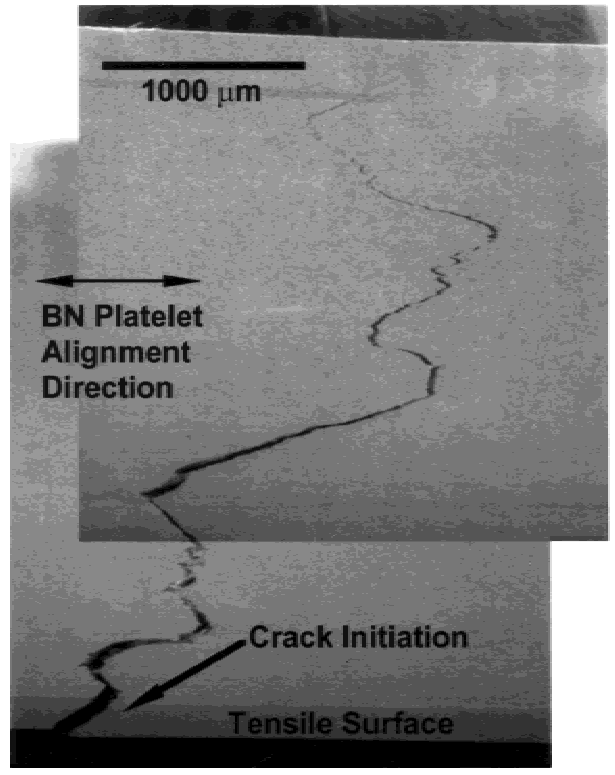

$\mathrm{BN}-22 \mathrm{HA}$

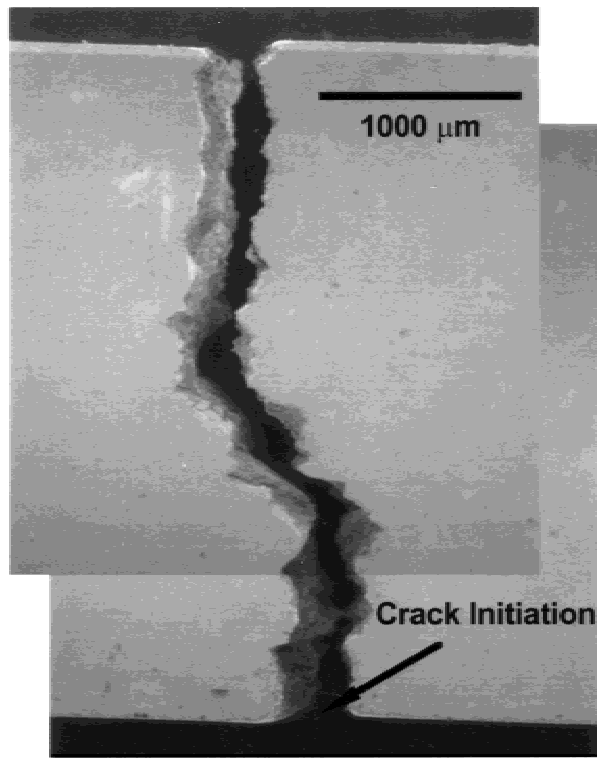

BN-31LA

Fig. 3. BN-22HA and BN-31LA samples fractured by flexure loading. The crack followed a more tortuous path in the sample with well-aligned $\mathrm{BN}$ grains.

pressing direction) in BN-22LA act as preexistent flaws, either due to the intrinsic weakness between basal planes or due to existing microcracks, reducing its strength.

The flexure strength of BN-31LA was $105 \mathrm{MPa}$, approximately 25 to $30 \mathrm{MPa}$ higher than measured for BN-22LA. Increasing the amount of additives would increase the strength of the hot-pressed billets by reducing the flaw size associated with porosity.

Crack deflection was observed in all three of the current BN monolithic billet configurations as the crack followed a tortuous path as it propagated through the thickness of the test specimen. This was most prevalent in BN-22HA, shown in Fig. 3 , and is a result of the highly aligned grains. In BN-31LA and BN-22LA (not shown), the propagating crack followed a much straighter path through the thickness of the sample.

\section{Summary}

Monolithic billets of $h$-BN were fabricated, varying both alignment of the boron nitride grains and the amount of oxide additives. The oxide additives formed crystalline phases that were primarily located between basal planes of boron nitride. Increased grain alignment and amount of additives resulted in increased flexural strength. Crack deflection was observed to be strongly influenced by grain alignment, increasing as the platelike grains were oriented perpendicular to the propagating crack.

Acknowledgment: We wish to thank Prof. Katherine Faber, Don Baskin, Tom Easley, and Jennifer Mawdsley for their help in reviewing the manuscript.

\section{References}

${ }^{1}$ N. J. Archer, "The Preparation and Properties of Pyrolytic Boron Nitride," High Temp. Chem. Inorg. Ceram. Mater., Proc. Conf., 1976, 30, 167-80 (1977).
${ }^{2}$ J. H. Edgar, "Crystal Structure, Mechanical Properties, and Thermal Properties of BN"; pp. 7-21 in Properties of Group III Nitrides. Edited by J. H. Edgar. INSPEC, London, U.K., 1994.

${ }^{3}$ A. Lipp, K. A. Schwetz, and K. Hunold, "Hexagonal Boron Nitride: Fabrication, Properties, and Applications," J. Eur. Ceram. Soc., 5, 3-9 (1989).

${ }^{4}$ A. W. Moore, "Characterization of Pyrolytic Boron Nitride for Semiconductor Materials Processing," J. Cryst. Growth, 106, 6-15 (1990).

${ }^{5}$ D. Goeuriot-Launay, G. Brayet, and F. Thevenot, "Boron Nitride Effect on the Thermal Shock Resistance of an Alumina Based Ceramic Composite," $J$. Mater. Sci. Lett., 5, 940-42 (1986).

${ }^{6} \mathrm{C}$. Doche and $\mathrm{F}$. Thevenot, "The $\mathrm{Si}_{3} \mathrm{~N}_{4}-\mathrm{BN}$ Ceramic Composite: Influence of Composition on Thermal Shock Resistance," Proceedings of the 11th International Symposium on Boron, Borides, and Related Compounds, Jpn. J. Appl. Phys. Ser., 10, 212-15 (1994).

${ }^{7}$ E. H. Lutz and M. V. Swain, "Fracture Toughness and Thermal Shock Behavior of Silicon Nitride-Boron Nitride Ceramics," J. Am. Ceram. Soc., 75 [1] 67-70 (1992).

${ }^{8}$ K. S. Mazdiyasni and R. Ruh, "High/Low Modulus $\mathrm{Si}_{3} \mathrm{~N}_{4}-\mathrm{BN}$ Composite for Improved Electrical and Thermal Shock Behavior," J. Am. Ceram. Soc., 64 [7] 415-19 (1981).

${ }^{9}$ W. Sinclair and H. Simmons, "Microstructure and Thermal Shock Behavior of BN Composites," J. Mater. Sci. Lett., 6, 627-29 (1987).

${ }^{10}$ R. Ruh, M. Kearns, A. Zangvil, and Y. Xu, "Phase and Property Studies of Boron Carbide-Boron Nitride Composites," J. Am. Ceram. Soc., 75 [4] 864-72 (1992).

${ }^{11} \mathrm{~S}$. Turan and K. M. Knowles, "High Resolution Transmission Electron Microscopy of the Planar Defect Structure of Hexagonal Boron Nitride," Phys. Status Solidi, 150, 227-37 (1995).

${ }^{12}$ D. Kovar, M. D. Thouless, and J. W. Halloran, "Crack Deflection and Propagation in Layered Silicon Nitride/Boron Nitride Ceramics," J. Am. Ceram. Soc., 81 [4] 1004-12 (1998).

${ }^{13}$ D. Kovar, B. H. King, R. W. Trice, and J. W. Halloran, "Fibrous Monolithic Ceramics," J. Am. Ceram. Soc., 80 [10] 2471-87 (1997).

${ }^{14}$ R. W. Trice, "The Elevated Temperature Mechanical Properties of Silicon Nitride/Boron Nitride Fibrous Monoliths"; Doctoral Dissertation. University of Michigan, Ann Arbor, MI, 1998.

${ }^{15}$ R. W. Trice and J. W. Halloran "Influence of Microstructure and Temperature on the Interfacial Fracture Energy of Silicon Nitride/Boron Nitride Fibrous Monolithic Ceramics," J. Am. Ceram. Soc., 82 [9] 2502-508 (1999).

${ }^{16} \mathrm{~L}$. N. Rusanova and L. I. Gorchakova, "Sintering of Turbostratic-Structure Boron Nitride Powders," Poroshk. Metall., 2 [314] 38-42 (1989).

${ }^{17}$ ASTM Standard C 373-72. American Society for Testing and Materials, West Conshohocken, PA, 1982.

${ }^{18}$ K. Liddel and D. P. Thompson, "X-ray Diffracton Data for Yttrium Silicates," Br. Ceram. Trans. J., 85, 17-22 (1985). 